\title{
Tissue-specific transcriptional regulation of epithelial/endothelial and mesenchymal markers during renovascular hypertension
}

\author{
LEANDRO RICARDO FERRAZ, BIANCA CARUSO MOREIRA, GABRIELA DE SOUZA RODRIGUES DE QUEIROZ, \\ REGIANE DE FREITAS FORMIGARI, MARCELO AUGUSTO MARRETO ESQUISATTO, MAIRA FELONATO, \\ ARMINDO ANTONIO ALVES, BRUNA FONTANA THOMAZINI and CAMILA ANDRÉA DE OLIVEIRA
}

Graduate Program in Biomedical Sciences, University Center of the Hermínio Ometto Foundation, Araras, São Paulo 13607-339, Brazil

Received February 19, 2019; Accepted July 22, 2019

DOI: $10.3892 / \mathrm{mmr} .2019 .10722$

\begin{abstract}
Epithelial-to-mesenchymal transition (EMT) and endothelial-to-mesenchymal transition are processes that can occur under different biological conditions, including tissue healing due to hypertension and oxidative stress. The purpose of the present study was to evaluate the differences in gene expression of epithelial/endothelial and mesenchymal markers in different tissues. A two-kidney, one-clip (2K1C) renovascular hypertension rat model was used. Hypertension was induced by the clipping of the left renal artery; the rats were randomized into sham and $2 \mathrm{~K} 1 \mathrm{C}$ groups and monitored for up to 4 weeks. The gene expressions of E-cadherin (E-cad), $\mathrm{N}$-cadherin $(\mathrm{N}$-cad), $\alpha$-smooth muscle actin ( $\alpha$-SMA), collagen I (COL1A1), collagen III (COL3A1) and hepatocyte growth factor (HGF) were determined by reverse transcription-PCR. The levels of the cytokines transforming growth factor- $\beta 1$, tumor necrosis factor- $\alpha$, interleukin (IL)-4, IL-6 and IL-10 were evaluated using ELISAs. The levels of thiobarbituric acid reactive substances and thiol groups were measured to evaluate oxidative stress. All analyses were performed on the liver, heart and kidneys tissues of sham and model rats. The 2K1C animals exhibited a higher systolic blood pressure, as well as cardiac hypertrophy and atrophy of the left kidney. Fibrotic alterations in the heart and kidneys were observed, as was an increase in the collagen fiber areas, and higher levels of inflammatory cytokines, which are associated with the increased expression of fibroproliferative and anti-fibrotic genes. Renovascular hypertension regulated epithelial/endothelial and mesenchymal markers, including E-cad, N-cad, $\alpha$-SMA and COL1A1 in the kidneys and heart.
\end{abstract}

Correspondence to: Dr Camila Andréa de Oliveira, Graduate Program in Biomedical Sciences, University Center of The Hermínio Ometto Foundation, Av. Maximiliano Barutto, 500 Jardim Universitário, Araras, São Paulo 13607-339, Brazil

E-mail: caol@fho.edu.br

Key words: cadherins, epithelial/endothelial-to-mesenchymal transition, gene expression, oxidative stress, two-kidney one-clip model
EMT in the kidneys was mediated by an increased level of inflammatory and profibrotic cytokines, as well as by oxidative stress. The data in the present study suggested that the expression of epithelial/endothelial and mesenchymal markers are differentially regulated by hypertension in the liver, heart and kidneys.

\section{Introduction}

Renovascular hypertension resulting from renal artery stenosis is an important cause of secondary hypertension that is often related to the activation of the renin-angiotensin system (RAS), leading to problems in many organs, including cardiac insufficiency (1). This condition, which affects $5 \%$ of patients suffering from systemic arterial hypertension, can be caused by atherosclerosis and is associated with cardiovascular disease (2). In the same way, poor renal function in cases of renovascular hypertension is associated with an increase in oxidative stress and markers of renal damage, indicated by inflammation and fibrosis (3). Inflammation and oxidative stress have synergistic effects on the pathophysiology of arterial hypertension and cardiovascular remodeling (4). Oxidative stress resulting from the imbalance between the production and degradation of reactive oxygen species (ROS) is one of the main causes of endothelial dysfunction, due to the decreased bioavailability of nitric oxide to react with superoxide anions, resulting in the formation of peroxynitrite (5).

Epithelial-to-mesenchymal transition (EMT) and endothelial-to-mesenchymal transition (EndMT) are complex and dynamic processes that are important for normal wound healing, but are deleterious in fibrogenic diseases, including hepatic, cardiac and renal fibrosis (6-8). During EMT/EndMT, epithelial/endothelial cells modify their phenotype and express markers of mesenchymal cells, with leads to an alteration of their functions; for example, the acquisition of the ability to migrate and synthesize interstitial matrix (9). Members of the cadherin family of transmembrane glycoproteins, including E-cadherin (E-cad) and N-cadherin (N-cad), represent the main components of adherens junctions (AJs), and are mediators of $\mathrm{Ca}^{2+}$-dependent adhesion between cells and promote intercellular binding to the actin of the cytoskeleton (10). E-cad and $\mathrm{N}$-cad are very similar in terms of sequence and structure, 
but demonstrate highly specific cell adhesion behavior (11). E-cad acts in the maintenance of epithelium integrity (12), while $\mathrm{N}$-cad is known to be a mediator of the connections between fibroblasts (13). The EMT process requires the inhibition of several genes encoding proteins responsible for cell adhesion, such as E-cad. However, there is an upregulation of genes encoding cytoskeletal proteins, such as $\mathrm{N}$-cad and $\alpha$-smooth muscle actin ( $\alpha$-SMA), that undergo intracellular rearrangements, allowing stroma invasion. In addition, there is an upregulation of extracellular matrix-associated proteins, such as fibronectin, collagen I/III and metalloproteinases (14).

There have been several previous studies concerning EMT in cancer $(15,16)$ and repair following damage $(17,18)$. However, little is known about the role of AJs, mediated by proteins such as E-cad and $\mathrm{N}$-cad, or the transdifferentiation of epithelial/endothelial and mesenchymal markers in cases of renovascular hypertension. Thus, it was hypothesized that epithelial/endothelial and mesenchymal markers are differentially regulated by hypertension in different tissues. In the present study, the effect of renovascular hypertension on the gene expression of epithelial/endothelial and mesenchymal markers was investigated, following inflammatory processes and oxidative stress in the liver, kidneys and cardiac muscle.

\section{Materials and methods}

Ethics declaration and animal care. All the surgical and experimental procedures carried out in the present study complied with the Care and Use of Laboratory Animals standards established by the National Institute of Health (NIH Publication 80-23, revised in 2011). The present study was carried out in accordance with Brazilian legal requirements (federal law 11794/2008) and were approved by the Animal Use Ethics Committee of the University Center of the Hermínio Ometto Foundation (protocol no. 036/2014). The work complied with the animal experimentation ethical standards of the Brazilian College of Animal Experimentation. The experiments used 18 male Wistar rats (age, 50 days) weighing 180-200 g obtained from the Animal Experimentation Center of the Hermínio Ometto Foundation. The animals were housed in cages (2-3 rats/cage) at a controlled temperature of $21-23^{\circ} \mathrm{C}$ and humidity of $60 \%$, with a $12 \mathrm{~h}$ light/dark cycle and free access to water and feed.

Experimental groups and induction of hypertension. The animals were randomly divided into two experimental groups and were anesthetized by intraperitoneal injection of ketamine $(100 \mathrm{mg} / \mathrm{kg})$ and xylazine $(10 \mathrm{mg} / \mathrm{kg})$. The left kidney was exposed using a small incision in the flank and the renal artery was dissected from the renal vein and the adjacent tissues. In 11 animals, a U-shaped silver clip with an internal diameter of $0.2 \mathrm{~mm}$ was placed around the renal artery [according to the 2-kidney, 1-clip (2K1C) model of renin-dependent hypertension], resulting in stenosis of the artery, as described by Goldblatt et al (19). The sham animals $(\mathrm{n}=7)$ underwent the same surgical procedure, but without insertion of the clip. After 4 weeks of hypertension induction, the animals were euthanized by deep anesthesia $(100 \mathrm{mg} / \mathrm{kg}$ ketamine and $10 \mathrm{mg} / \mathrm{kg}$ xylazine) and the liver, heart and kidneys were removed.
Monitoring of systolic blood pressure and body weight. The systolic blood pressure was measured by the noninvasive method of tail plethysmography. Cuffs coupled to pressure transducers were placed around the tails of the awake animals, which had been previously warmed in a cabinet at $37^{\circ} \mathrm{C}$. The pressure change data were acquired using a Power Lab 4/S analog-to-digital converter (ADInstruments Pty Ltd.) and the results were presented as the average of three consecutive measurements for each animal. Prior to the first arterial pressure measurement, the animals were adapted to the procedure by placing them in the acrylic container on 5 consecutive days. The arterial pressure and body weight were determined on a weekly basis during the 4 weeks of the study. The model was deemed to have been successfully established if the systolic blood pressure was higher than $160 \mathrm{mmHg}$ after 4 weeks of operation.

Morphometry and stereology. Representative areas of the hepatic tissue, left cardiac ventricle and renal cortex were imaged using a Leica DM2000 light microscope (magnification, $\mathrm{x} 400$ ). The samples were fixed in formaline $10 \%$ for $48 \mathrm{~h}$ at room temperature. Samples were embedded in Paraplast ${ }^{\circledR}$ (Sigma-Aldrich; Merck KGaA) and dehydrated using increasing alcohol series. This was followed by morphometric and stereological analyses performed with Image-Pro Plus ${ }^{\circledR}$ v.4.5.0.29 software (Media Cybernetics, Inc.). The analyses used $5 \mu \mathrm{m}$ histological sections, with spacings between the sections of $40 \mu \mathrm{m}$ (liver and heart) and $20 \mu \mathrm{m}$ (kidney). The histological sections were treated at $37^{\circ} \mathrm{C}$ using a combined histochemical technique employing $1 \%$ Alcian Blue $(\mathrm{pH} 2.5)$ with $0.5 \%$ Periodic Acid with Schiff Reagent (AB + PAS) for 15,5 and $10 \mathrm{~min}$, respectively, or using a traditional Mallory's trichrome (MT) staining solution at $37^{\circ} \mathrm{C}$ for $35 \mathrm{~min}$.

Stereological analysis of the liver was performed using the previous samples treated with $\mathrm{AB}+\mathrm{PAS}$ and imaged using a Leica DM2000 light microscope (magnification, x400). A grid of 475 intersections was selected for each of 10 images, totaling 4,750 intersections per animal, in order to determine the frequencies of interstitial and cellular components, and the corresponding areas occupied. The interstitial components observed were the connective tissue and the blood vessels, while the cellular components were the hepatocyte cytoplasm and the mono- or binucleate nucleus of these cells. The total number of hepatocytes was counted in 10 fields of view, with a morphometric assessment of the area of these cells also carried out.

Evaluation of the cardiac tissue employed samples stained with MT and imaged at x400 magnification. The analysis involved the determination of the number of cardiomyocytes and the area occupied, considering cells in the transversal plane occupying the entire image in question, as well as the percentage of the area occupied by collagen fibers in regions with a predominance of fibers cut in the longitudinal plane. This evaluation used 10 images, each with a grid with 540 intersections, totaling 5,400 intersections per animal. This procedure enabled the determination of the frequency of areas with connective tissue associated with the cardiac cells.

The morphometric analyses of the right and left renal cortex were used to determine the corpuscle and glomerular capillary diameters, considering 10 glomeruli. For this, samples 
subjected to the $\mathrm{AB}+\mathrm{PAS}$ histochemical procedure were photo-documented at $\mathrm{x} 400$ magnification. The stereological analysis used samples stained with MT and photo-documented at 400x magnification. A grid with 690 intersections was applied to each of 10 images of the renal cortex, totaling 6,900 intersections per animal, in order to determine the proportions of the kidney components (blood vessels, connective tissue, glomerular corpuscles and tubular epithelium and lumen).

ELISA. Total proteins were extracted from hepatic, cardiac and renal tissues samples using a detergent-based extraction buffer (T-PER Tissue Protein Extraction Reagent; Thermo Fisher Scientific, Inc.) containing a protease inhibitor cocktail (Roche Diagnostics). The tissue samples were macerated in buffer [1:20 (w/v) of tissue to T-PER Reagent], centrifuged at $1,200 \mathrm{x}$ g for $10 \mathrm{~min}$ at $4^{\circ} \mathrm{C}$ and the supernatant was collected. The total protein present in each sample was quantified using the Bradford assay. The levels of interleukin (IL)-4, IL-6, IL-10, tumor necrosis factor- $\alpha(\mathrm{TNF}-\alpha)$ and transforming growth factor- $\beta 1$ (TGF- $\beta 1$ ) were determined using Rat Platinum ELISA kits (cat. nos. 5018354, 13467093, 15532067, 13427093 and 15512057, respectively; eBioscience; Thermo Fisher Scientific, Inc.), according to the manufacturer's instructions. Standard curves were constructed for the cytokine protein concentration $(\mathrm{pg} / \mathrm{ml})$ plotted against the mean optical density for the replicates. The concentrations of the cytokines in the samples (in duplicate) were determined using the standard curves.

Evaluation of the redox state. Lipid peroxidation was evaluated by quantification of the levels of thiobarbituric acid reactive substances (TBARS) in hepatic, cardiac and renal tissue homogenates, as described previously (20). The reduced thiols (-SH groups) of proteins were determined using 5.5'-dithiobis(2-nitrobenzoic acid), as described by Faure and Lafond (21).

Determination of $m R N A$ expression by reverse transcription $(R T)-P C R$. Total RNA was extracted from the liver, left cardiac ventricle and kidneys of the sham and $2 \mathrm{~K} 1 \mathrm{C}$ animals using TRIzol $^{\circledR}$ reagent (Invitrogen; Thermo Fisher Scientific, Inc.), followed by quantification using UV spectrophotometry at a wavelength of $260 \mathrm{~nm}$. The quality was evaluated using $1 \%$ agarose gel electrophoresis. Generation of cDNA was performed using RT with $2 \mu \mathrm{g} / \mu \mathrm{l}$ total RNA with random primers $(150 \mathrm{ng} / \mu \mathrm{l}), \mathrm{dNTPs}(10 \mathrm{mmol} / \mu \mathrm{l})$ and the SuperScript II Reverse Transcriptase kit at $25^{\circ} \mathrm{C}$ for $10 \mathrm{~min}$, followed by an incubation at $42^{\circ} \mathrm{C}$ for $50 \mathrm{~min}$ and at $70^{\circ} \mathrm{C}$ for $15 \mathrm{~min}$ (Invitrogen; Thermo Fisher Scientific, Inc.) in a final volume of $20 \mu \mathrm{l}$, according of the manufacturer's protocol. mRNA expression was determined by semiquantitative RT-PCR using a PCR thermocycler (AmpliTherm) in a final volume of $25 \mu \mathrm{l}$ containing $1 \mu \mathrm{l} \mathrm{cDNA}$, 10X PCR buffer (10 mM Tris-HCL; pH 8.8) (Invitrogen; Thermo Fisher Scientific, Inc.), 200-400 mM of each dNTP, 0.2 pmol of each primer, $1.6-2.0 \mathrm{mM} \mathrm{MgCl}_{2}$, and $0.04 \mathrm{U}$ Taq DNA polymerase (Invitrogen; Thermo Fisher Scientific, Inc.). The primers specific for each gene used for PCR were: E-cad, forward (F) 5'-GCAGTTCTGCCAGAGAAACC-3' and reverse (R) 5'-AATCCTGCTTCCAGGGAGAT-3'; N-cad, F 5'-TGT TGCTGAAGAAAACCAAG-3' and R 5'-GGCGACTCTCTG TCCAGAAC-3'; $\alpha$-SMA, F 5'-CACCATCGGGAATGAACG
Table I. Characteristics of the sham and 2K1C animals at the end of the experimental period.

\begin{tabular}{lcc}
\hline Parameter & Sham $(\mathrm{n}=7)$ & $2 \mathrm{~K} 1 \mathrm{C}(\mathrm{n}=11)$ \\
\hline Body weight $(\mathrm{g})$ & $360 \pm 29$ & $382 \pm 22$ \\
SBP $(\mathrm{mmHg})$ & $148 \pm 4$ & $203 \pm 9^{\mathrm{a}}$ \\
Liver weight $(\mathrm{g})$ & $9.24 \pm 0.36$ & $8.74 \pm 0.19$ \\
HWI $(\mathrm{g} / \mathrm{g})$ & $0.033 \pm 0.001$ & $0.031 \pm 0.001$ \\
Heart weight $(\mathrm{g})$ & $1.005 \pm 0.091$ & $1.391 \pm 0.097^{\mathrm{a}}$ \\
CWI $(\mathrm{g} / \mathrm{g})$ & $0.0028 \pm 0.0001$ & $0.0036 \pm 0.0001^{\mathrm{a}}$ \\
Kidney weight $(\mathrm{g})$ & & \\
Right & $1.25 \pm 0.07$ & $1.63 \pm 0.13^{\mathrm{a}, \mathrm{b}}$ \\
Left & $1.28 \pm 0.11$ & $0.93 \pm 0.07^{\mathrm{a}}$ \\
KWI (g/g) & & \\
Right & $0.0035 \pm 0.0001$ & $0.0042 \pm 0.0002^{\mathrm{a}, \mathrm{b}}$ \\
Left & $0.0036 \pm 0.0001$ & $0.0025 \pm 0.0002^{\mathrm{a}}$ \\
Left kidney/right & $1.018 \pm 0.04$ & $0.599 \pm 0.06$ \\
kidney ratio & & \\
\end{tabular}

Values are expressed as the mean \pm SEM of three independent experiments. HWI, liver weight/body weight. ${ }^{\mathrm{a}} \mathrm{P}<0.05 \mathrm{vs}$. sham; ${ }^{\mathrm{b}} \mathrm{P}<0.001$ vs. $2 \mathrm{~K} 1 \mathrm{C}$ contralateral kidney. SBP, systolic blood pressure; HWI, hepatic weight index; CWI, cardiac weight index; KWI, kidney weight index; 2K1C, 2 kidney 1 clip.

CT-3' and R 5'-CGAGAGGACGTTGTTAGCATAGAG-3'; collagen I (COL1A1), F 5'-GGAAGCTTGGTCCTCTTG CT-3' and R 5'-GTTAGGCTCCTTCAATAGTCC-3'; collagen III (COL3A1), F 5'-AGGCCAATGGCAATGTAAAG-3' and R 5'-CAATGTCATAGGGTGCGATA-3'; hepatocyte growth factor (HGF), F 5'-TTCCCAGCTAGTCTATGGAC-3' and R 5'-TGGTGCTGACTGCATTTCTC-3'; and $\beta$-actin, F 5'-AGA GGGAAATCGTGCGTGACA-3' and R 5'-CGATAGTGA TGACCTGACCGTCA-3'. The amplification conditions were as follows: Initial denaturation at $93^{\circ} \mathrm{C}$ for $3 \mathrm{~min}$, followed by 26 cycles for the $\beta$-actin gene, 30 cycles for E-cad, N-cad and COL3A1, 32 cycles for $\alpha$-SMA, and 34 cycles for COL1A1 and HGF. The cycles consisted of a denaturation step at $94^{\circ} \mathrm{C}$ for $30 \mathrm{sec}(\beta$-actin, E-cad, N-cad, COL1A1 and COL3A1) or $1 \mathrm{~min}$ $\left(\alpha-\right.$ SMA and HGF); annealing at $55^{\circ} \mathrm{C}$ for $30 \mathrm{sec}$ (E-cad, $\mathrm{N}$-cad, $\mathrm{COL} 1 \mathrm{~A} 1$ and $\mathrm{COL} 3 \mathrm{~A} 1)$, at $57^{\circ} \mathrm{C}$ for $30 \mathrm{sec}\left(\beta\right.$-actin), or at $59^{\circ} \mathrm{C}$ for $1 \mathrm{~min}\left(\alpha\right.$-SMA and HGF); extension at $72^{\circ} \mathrm{C}$ for $30 \mathrm{sec}(\beta$-actin, E-cad, N-cad, COL1A1 and COL3A1) or $1 \mathrm{~min}(\alpha-\mathrm{SMA}$ and HGF). The PCR products were separated by $1.5 \%$ agarose gel electrophoresis and were stained with ethidium bromide. The gel was imaged using the Syngen G:Box ${ }^{\circledR}$ system, followed by densitometric quantification of the bands using Scion Image 4.0 software (Scion Corporation). The relative expression of the genes investigated were obtained by normalization with the expression values obtained for the $\beta$-actin gene.

Statistical analysis. The data are presented as the mean \pm SEM, considering the results of three independent experiments. Differences between groups were evaluated using the unpaired Student's t-test and one-way ANOVA followed by the Bonferroni post-hoc test. Statistical analyses were performed using GraphPad Prism v. 5.0 software (GraphPad Software, 

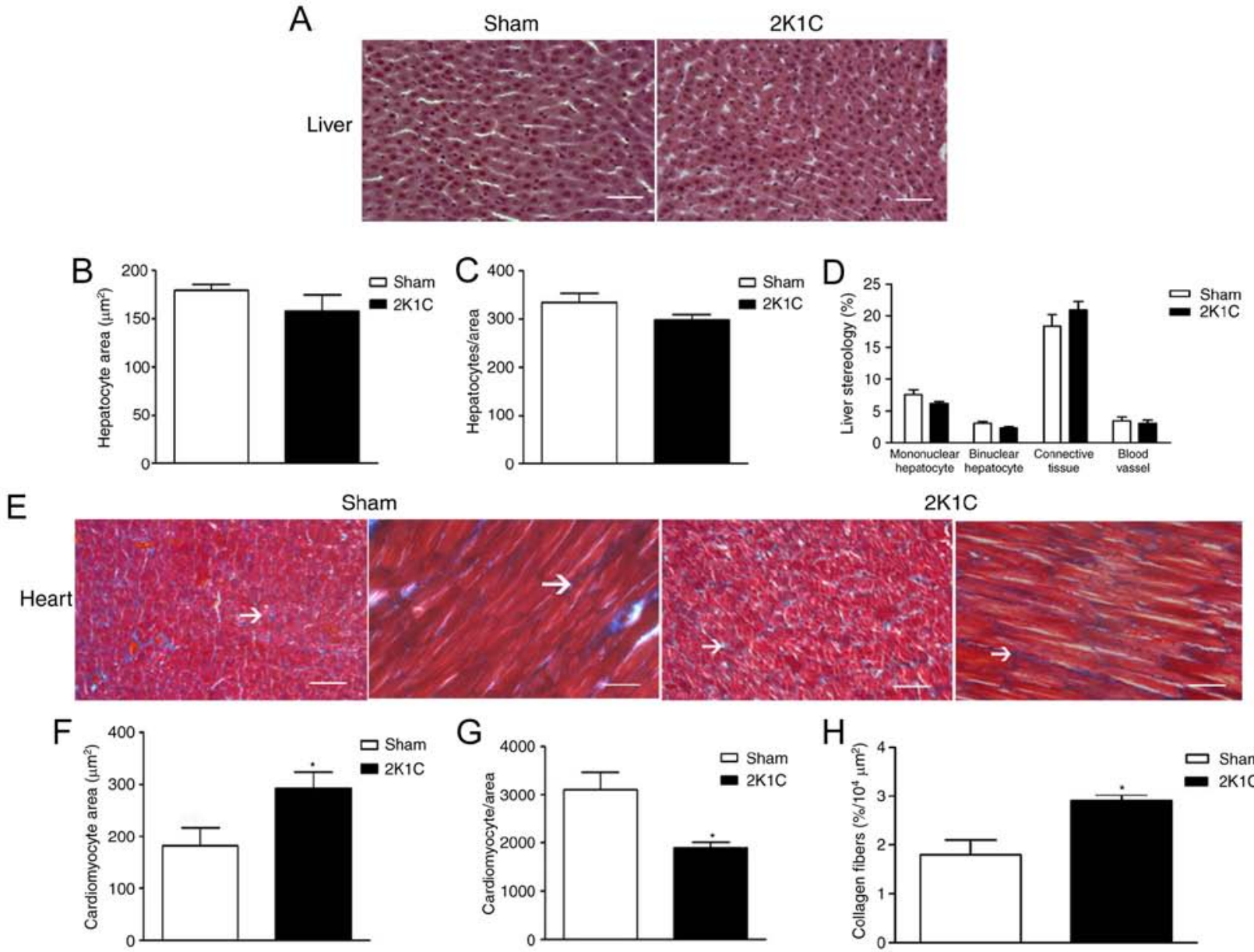

$2 \mathrm{~K} 1 \mathrm{C}$
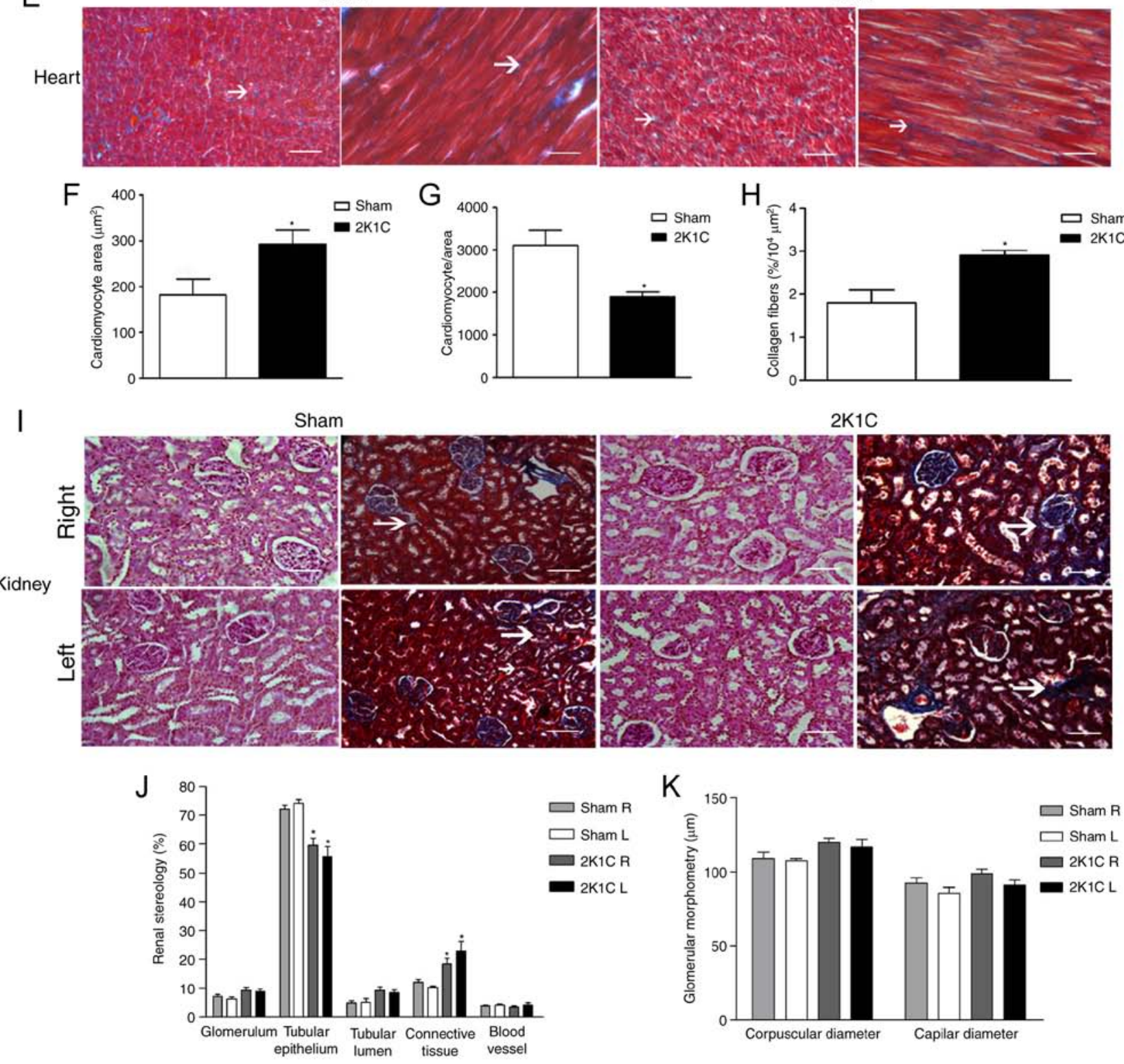

Figure 1. Histology pattern, morphometry and stereology results. (A) Liver sections stained with AB + PAS show similar structures in both the sham and $2 \mathrm{~K} 1 \mathrm{C}$ groups, with the liver morphometry and stereology results exhibiting no statistical differences between the groups in terms of (B) the hepatocyte area, (C) the number of hepatocyte per unit of area and (D) stereology. (E) Heart sections stained with MT, arrows indicate connective tissue; the 2K1C group showed an increase in $(\mathrm{F})$ cardiomyocyte area combined with a reduction in the (G) frequency of cardiomyocytes per unit area. (H) In accordance with this pattern, an increased area occupied by connective tissue was observed. (I) R and L kidneys stained with AB + PAS and MT. (I) The 2K1C group showed more area occupied by connective tissue (as indicated by the arrow) and less area occupied by $(\mathrm{J})$ tubular epithelium. (K) There were no differences in glomerular morphometry between the groups. Blue areas in MT stained samples indicates areas with collagen fibers, indicative of connective tissue. Scale bar, $50 \mu \mathrm{m}$. ${ }^{*} \mathrm{P}<0.05$ vs. sham. AB + PAS, Alcian Blue ( $\mathrm{pH}$ 2.5) with Periodic Acid-Schiff; 2K1C, 2 kidney 1 clip; R, right; L, left; MT, Mallory's trichrome. 
A
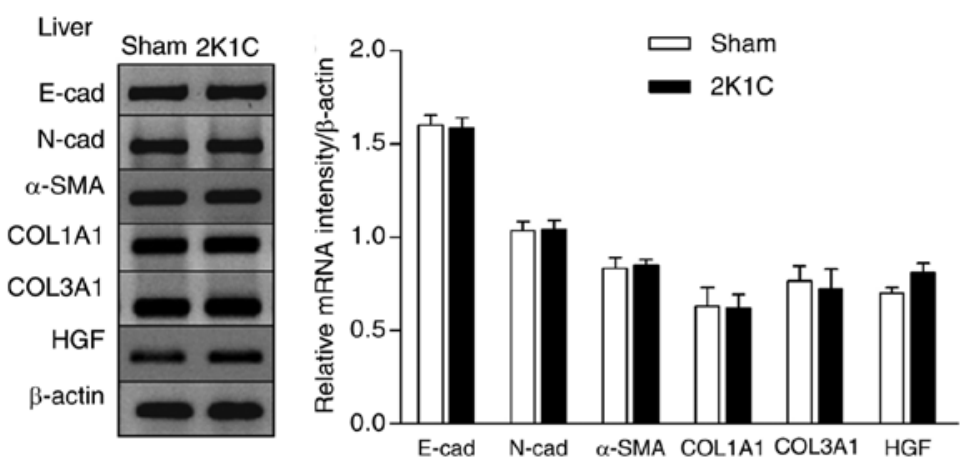

B
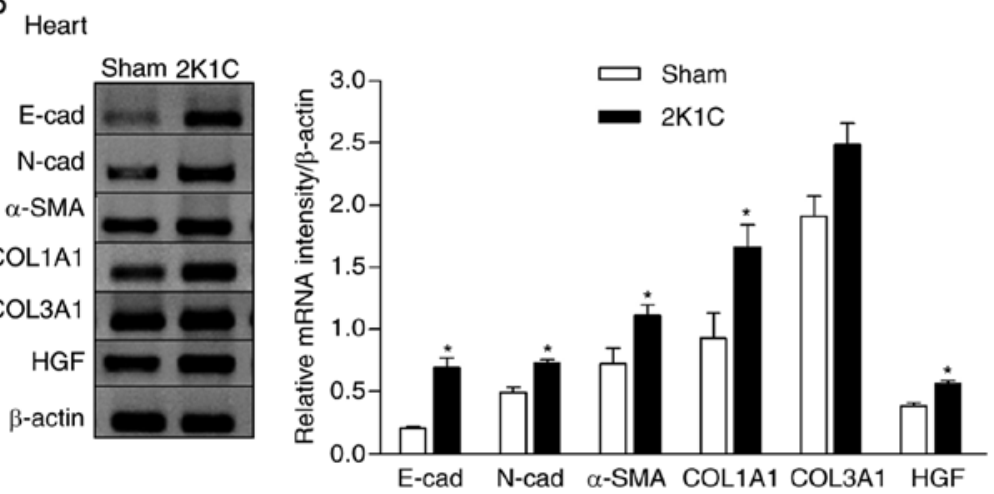

C
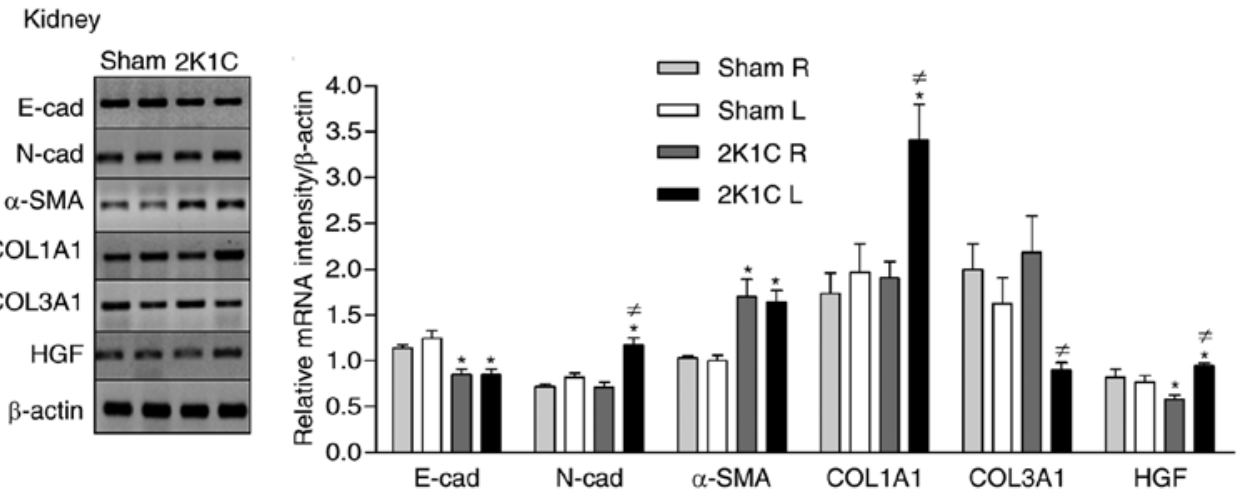

Figure 2. Effect of renovascular hypertension on the expression of E-cad, N-cad, $\alpha$-SMA, COL1A1, COL3A1 and HGF genes. Expression was detected using reverse transcription-PCR in the (A) liver, (B) heart and (C) kidneys with densitometric analysis was carried out for each gene for the sham and $2 \mathrm{~K} 1 \mathrm{C}$ groups Values are expressed as the mean \pm SEM for each group. ${ }^{7} \mathrm{P}<0.05$ vs. respective sham; ${ }^{\circ} \mathrm{P}<0.05$ vs. contralateral $2 \mathrm{~K} 1 \mathrm{C}$ kidney. $2 \mathrm{~K} 1 \mathrm{C}, 2 \mathrm{kidney} 1$ clip; E-cad, E-cadherin; N-cad, N-cadherin; $\alpha$-SMA, $\alpha$-smooth muscle actin; COL1A1, collagen I; COL3A1, collagen III; HGF, hepatocyte growth factor; L, left; R, right.

Inc.). $\mathrm{P}<0.05$ was considered to indicate a statistically significant difference.

\section{Results}

Biometric and morphometric analyses. Table I details the characteristics of the sham and $2 \mathrm{~K} 1 \mathrm{C}$ groups as assessed on the day of the experiment. Compared with the sham group, the $2 \mathrm{~K} 1 \mathrm{C}$ animals subjected to the clipping of the renal artery exhibited higher systolic arterial pressure $(203 \pm 9$ vs. $148 \pm 4 \mathrm{mmHg}$ in sham; $\mathrm{P}=0.0003$ ), increased heart weight $(1.39 \pm 0.09$ vs. $1.005 \pm 0.09 \mathrm{~g}$ in sham, $\mathrm{P}=0.01)$ and right kidney weight ( $1.63 \pm 0.13$ vs. $1.25 \pm 0.07 \mathrm{~g}$ in sham, $\mathrm{P}=0.04$; Table I). The body and liver weights were similar for the two groups. Histological analysis showed that the $2 \mathrm{~K} 1 \mathrm{C}$ animals had a normal hepatic cytoarchitecture, without any changes in the hepatocyte number or area. The areas occupied by connective tissue, blood vessels, and mono- and binucleate nuclei were similar for all the animals (Fig. 1A-D).

Hypertension led to cardiac hypertrophy, as shown by a $29 \%$ increase in the heart weight index (Table I), and was associated with a decrease in the number of cardiomyocytes $(1,894 \pm 114.7$ vs. $3,107 \pm 357.1$ in sham, $P=0.005$; Fig. $1 \mathrm{E}$ and $\mathrm{G})$ and an increase in their area $\left(292.9 \pm 30.54\right.$ vs. $181.6 \pm 35.43 \mu \mathrm{m}^{2}$ in sham, $\mathrm{P}=0.04$; Fig. $1 \mathrm{E}$ and $\mathrm{F}$ ) in the animals in the $2 \mathrm{~K} 1 \mathrm{C}$ group. This was accompanied by an increase in the area occupied by collagen fibers in the cardiac tissue of the $2 \mathrm{~K} 1 \mathrm{C}$ animals compared with the sham group $(2.90 \pm 0.12$ vs. $1.80 \pm 0.30 \% / 10^{4} \mu \mathrm{m}^{2}$, respectively, $\mathrm{P}=0.004$; Fig. $1 \mathrm{E}$ and $\mathrm{H}$ ).

By contrast, the weight value of the left kidney in the $2 \mathrm{~K} 1 \mathrm{C}$ animals $(0.93 \pm 0.07 \mathrm{~g})$ was lower in comparison to the contralateral kidney $(1.63 \pm 0.13 \mathrm{~g}, \mathrm{P}=0.0001)$ and the sham 
Table II. Pro- and anti-inflammatory profile in 2K1C experimental model.

A, Liver

\begin{tabular}{lcr}
\hline Protein $(\mathrm{pg} / \mathrm{ml})$ & Sham $(\mathrm{n}=7)$ & $2 \mathrm{~K} 1 \mathrm{C}(\mathrm{n}=11)$ \\
\hline TGF- $\beta 1$ & $353.6 \pm 42.9$ & $599.4 \pm 80.32^{\mathrm{a}}$ \\
TNF- $\alpha$ & $813.9 \pm 52$ & $1,114.5 \pm 99.61^{\mathrm{a}}$ \\
IL-4 & $71.9 \pm 2$ & $69.0 \pm 4$ \\
IL-10 & $782.9 \pm 83$ & $812.8 \pm 23$ \\
IL-6 & $10,135.6 \pm 376$ & $9,475.9 \pm 253$ \\
\hline
\end{tabular}

B, Heart

\begin{tabular}{lcr}
\hline Protein $(\mathrm{pg} / \mathrm{ml})$ & Sham $(\mathrm{n}=7)$ & $2 \mathrm{~K} 1 \mathrm{C}(\mathrm{n}=11)$ \\
\hline TGF- $\beta 1$ & $89.05 \pm 4$ & $115.0 \pm 4^{\mathrm{a}}$ \\
TNF- $\alpha$ & $2,616.8 \pm 239$ & $2,247.4 \pm 95$ \\
IL-4 & $20.9 \pm 1$ & $20.7 \pm 2$ \\
IL-10 & $1,459.1 \pm 112$ & $1,468.8 \pm 143$ \\
IL-6 & $3,728.9 \pm 80$ & $3,682.5 \pm 243$ \\
& & \\
C, Kidney & & \\
\hline
\end{tabular}

\begin{tabular}{lcccc}
\hline & \multicolumn{2}{c}{ Sham $(\mathrm{n}=7)$} & \multicolumn{2}{c}{$2 \mathrm{~K} 1 \mathrm{C}(\mathrm{n}=11)$} \\
\cline { 2 - 5 } Protein $(\mathrm{pg} / \mathrm{ml})$ & Right & Left & Right & Left \\
\hline TGF- $\beta 1$ & $318.0 \pm 31$ & $438.6 \pm 40$ & $396.6 \pm 44$ & $631.2 \pm 2^{\mathrm{b}, \mathrm{c}}$ \\
TNF- $\alpha$ & $3,138.7 \pm 56$ & $3,103.6 \pm 279$ & $3,337.8 \pm 264$ & $3,175.5 \pm 447$ \\
IL-4 & $99.7 \pm 6$ & $104.9 \pm 6$ & $101.6 \pm 5$ & $111.9 \pm 5$ \\
IL-10 & $1,854.4 \pm 64$ & $1,844.8 \pm 100$ & $1,859.8 \pm 98$ & $1,812.4 \pm 66$ \\
IL-6 & $8,855.3 \pm 223$ & $8,333.1 \pm 267$ & $8,444.7 \pm 287$ & $9,896.9 \pm 252^{\mathrm{b}, \mathrm{c}}$ \\
\hline
\end{tabular}

Values are expressed as the mean $\pm \mathrm{SEM}$ of three independent experiments. ${ }^{\mathrm{a}} \mathrm{P}<0.05$ vs. sham; ${ }^{\mathrm{b}} \mathrm{P}<0.05 \mathrm{vs}$. contralateral $2 \mathrm{~K} 1 \mathrm{C}$ kidney; ${ }^{\mathrm{c}} \mathrm{P}<0.05$ vs. sham. 2 K1C, 2 kidney 1 clip; TGF- $\beta 1$, transforming growth factor- $\beta 1$; TNF- $\alpha$, tumor necrosis factor- $\alpha$; IL, interleukin.

group $(1.28 \pm 0.11 \mathrm{~g}, \mathrm{P}=0.012$; Table I). The left kidney/right kidney ratio was lower in the $2 \mathrm{~K} 1 \mathrm{C}$ animals than in the sham group (Table I). Renovascular hypertension also led to fibrotic changes in the stenotic kidney, as shown by the greater area of the renal cortex occupied by connective tissue $(22.98 \pm 3.33 \%)$ compared with the sham group $(10.32 \pm 0.37 \%$; $\mathrm{P}=0.01$; Fig. 1I and J). This was supported by a decrease of the area occupied by epithelium in the $2 \mathrm{~K} 1 \mathrm{C}$ animals $(55.62 \pm 3.5$ vs. $74.29 \pm 1.3 \%$, $\mathrm{P}=0.003$; Fig. 1I and J). No differences between the groups were observed for the remaining parameters determined for both kidneys (Fig. 1J and K).

Inflammatory and fibroproliferative profiles. The $2 \mathrm{~K} 1 \mathrm{C}$ group showed increases in the levels of the inflammatory cytokine TNF- $\alpha$ in the liver $(1,114.5 \pm 99.6$ vs. $813.9 \pm 52 ; \mathrm{P}=0.04)$ and IL-6 in the stenotic kidney $(9,896.9 \pm 252$ vs. $8,333.1 \pm 267$; $\mathrm{P}=0.004$ ) compared with the sham group (Table II). No differences between the groups were observed for the antiinflammatory cytokines IL-4 and IL-10 in the liver, heart and kidneys. However, there were increases in the levels of the fibroproliferative cytokine TGF- $\beta 1$ in the liver, heart and stenotic kidney in the $2 \mathrm{~K} 1 \mathrm{C}$ group $(599.4 \pm 80.3$ vs. $353.6 \pm 42.9$, $\mathrm{P}=0.04 ; 115.0 \pm 4$ vs. $89.05 \pm 4, \mathrm{P}=0.004 ; 631.2 \pm 42$ vs. $438.6 \pm 40$, $\mathrm{P}=0.01$; respectively; Table II).

Redox and antioxidant status. The levels of TBARS, an indicator of lipid peroxidation, were higher in the right $(0.021 \pm 0.002)$ and left kidneys $(0.022 \pm 0.004)$ of the $2 \mathrm{~K} 1 \mathrm{C}$ animals compared with the sham group $(0.017 \pm 0.001$ and $0.012 \pm 0.003$, respectively; $\mathrm{P}=0.01$; Table III). No differences between the experimental groups were observed for this parameter in the liver and heart. The level of -SH groups, indicative of antioxidant capacity, was only increased in the heart of the $2 \mathrm{~K} 1 \mathrm{C}$ animals $(1.376 \pm 0.208)$ compared with the sham group $(0.996 \pm 0.118, \mathrm{P}=0.01$; Table III $)$.

Effect of renovascular hypertension on the mRNA expression of genes involved in fibrosis and EMT/EndMT. The hepatic mRNA expressions of the E-cad, N-cad, COL1A1, COL3A1, $\alpha$-SMA and HGF were not affected by hypertension (Fig. 2A). 
Table III. Parameters of oxidative stress.

A, Liver

\begin{tabular}{lrr}
\hline Analysis & Sham $(\mathrm{n}=7)$ & $2 \mathrm{~K} 1 \mathrm{C}(\mathrm{n}=11)$ \\
\hline TBARS $(\mathrm{nmol} / \mu \mathrm{g}$ protein) & $0.022 \pm 0.004$ & $0.023 \pm 0.008$ \\
-SH groups $(\mu \mathrm{mol} / \mu \mathrm{g}$ protein $)$ & $0.770 \pm 0.460$ & $1.053 \pm 0.273$ \\
\hline
\end{tabular}

B, Heart

\begin{tabular}{llr}
\hline Analysis & Sham $(\mathrm{n}=7)$ & $2 \mathrm{~K} 1 \mathrm{C}(\mathrm{n}=11)$ \\
\hline TBARS (nmol $/ \mu \mathrm{g}$ protein) & $0.003 \pm 0.001$ & $0.004 \pm 0.002$ \\
-SH groups $(\mu \mathrm{mol} / \mu \mathrm{g}$ protein) & $0.996 \pm 0.118$ & $1.376 \pm 0.208^{\mathrm{a}}$ \\
\hline
\end{tabular}

C, Kidney

\begin{tabular}{|c|c|c|c|c|}
\hline \multirow[b]{2}{*}{ Analysis } & \multicolumn{2}{|c|}{ Sham $(n=7)$} & \multicolumn{2}{|c|}{$2 \mathrm{~K} 1 \mathrm{C}(\mathrm{n}=11)$} \\
\hline & Right & Left & Right & Left \\
\hline TBARS (nmol/ $\mu \mathrm{g}$ protein) & $0.017 \pm 0.001$ & $0.012 \pm 0.003$ & $0.021 \pm 0.002^{\mathrm{a}}$ & $0.022 \pm 0.004^{\mathrm{a}}$ \\
\hline -SH groups $(\mu \mathrm{mol} / \mu \mathrm{g}$ protein $)$ & $0.972 \pm 0.196$ & $0.881 \pm 0.094$ & $1.045 \pm 0.025$ & $1.042 \pm 0.090$ \\
\hline
\end{tabular}

Values are expressed as the mean \pm SEM of three independent experiments. ${ }^{a} \mathrm{P}=0.01 \mathrm{vs}$. sham. $2 \mathrm{~K} 1 \mathrm{C}, 2$ kidney 1 clip; TBARS, thiobarbituric acid reactive substances.

The hearts of the $2 \mathrm{~K} 1 \mathrm{C}$ animals showed increased mRNA expression of the E-cad $(0.69 \pm 0.08), \mathrm{N}$-cad $(0.73 \pm 0.02)$, $\alpha$-SMA (1.11 \pm 0.09$),$ COL1A1 (1.66 \pm 0.18$)$ and HGF $(0.56 \pm 0.02)$ compared with the sham group (E-cad, $0.2 \pm 0.02, \mathrm{P}=0.0001$; $\mathrm{N}$-cad, 0.49 $\pm 0.04, \mathrm{P}=0.0001 ; \alpha-\mathrm{SMA}, 0.72 \pm 0.13, \mathrm{P}=0.02$; COL1A1, 0.93 $\pm 0.2, \mathrm{P}=0.02 ; \mathrm{HGF}, 0.38 \pm 0.03, \mathrm{P}=0.0003)$. No significant change in the expression of the COL3A1 gene was observed (Fig. 2B). Hypertension decreased the renal mRNA expression of the E-cad gene (Right-2K1C $0.85 \pm 0.06$ vs. sham $1.14 \pm 0.03, \mathrm{P}=0.002$; Left- $2 \mathrm{~K} 1 \mathrm{C} 0.85 \pm 0.06$ vs. sham $1.25 \pm 0.08$, $\mathrm{P}=0.001$ ) and increased expression of the $\alpha$-SMA (Right-2K1C $1.69 \pm 0.19$ vs. sham $1.03 \pm 0.03, \mathrm{P}=0.01$; Left- $2 \mathrm{~K} 1 \mathrm{C} 1.63 \pm 0.13$ vs. sham $1.00 \pm 0.06, \mathrm{P}=0.002)$. However, increased expression of the $\mathrm{N}$-cad $(2 \mathrm{~K} 1 \mathrm{C} 1.17 \pm 0.08$ vs. sham $0.82 \pm 0.05, \mathrm{P}=0.006)$ and COL1A1 (2K1C $3.41 \pm 0.39$ vs. sham $1.96 \pm 0.32, \mathrm{P}=0.02)$, and the decreased expression of the COL $3 \mathrm{~A} 1$ gene $(2 \mathrm{~K} 1 \mathrm{C}$ $0.89 \pm 0.08$ vs. sham $1.63 \pm 0.28, \mathrm{P}=0.008$ ) was only observed in the left stenotic kidney. The $2 \mathrm{~K} 1 \mathrm{C}$ group presented differential regulation of HGF expression in the two kidneys (Fig. 2C). Hypertension increased the mRNA expression of HGF in the left kidney $(2 \mathrm{~K} 1 \mathrm{C} 0.94 \pm 0.03$ vs. sham $0.77 \pm 0.07, \mathrm{P}=0.02)$ but decreased the expression of this gene in the contralateral kidney ( $2 \mathrm{~K} 1 \mathrm{C} 0.58 \pm 0.05$ vs. sham $0.82 \pm 0.09, \mathrm{P}=0.02$; Fig. $2 \mathrm{C}$ ).

\section{Discussion}

In the $2 \mathrm{~K} 1 \mathrm{C}$ renovascular hypertension model, there is a chronic decrease of the blood flow and consequently of the renal perfusion pressure, resulting in elevated plasma renin levels. This is associated with an increase in the level of angiotensin II, which in turn leads to increased arterial pressure (22). In addition, prolonged exposure to angiotensin II contributes to the development of cardiovascular hypertrophy and remodeling (23). Left renal artery clamping leads to a hypertrophic response in the myocardium. In the present study, clamping led to an increased cardiac mass and cardiomyocyte area observed for the $2 \mathrm{~K} 1 \mathrm{C}$ animals. Thus, hypertension caused the myocardium to adapt to the increased load, with this adaptive response eventually resulting in an increased cardiac mass (24). The weight difference found between the clipped and non-clipped kidneys in the present study was also indicative of the effectiveness of the surgically induced experimental model. The findings of the present study suggested that the contralateral (non-clipped) kidney was able to prevent an increase in the blood volume and consequent additional increase in the arterial pressure. This is consistent with a previous study where a clip with a $0.2 \mathrm{~mm}$ aperture obstructed $>70 \%$ of the renal blood flow and led to renovascular hypertension (25).

The increased production of the inflammatory factors TGF- $\beta 1$, TNF- $\alpha$ and IL- 6 in the different organs of the hypertensive animals was indicative of the existence of an inflammatory process (26). Cardiovascular damage caused by excessive stimulation of the RAS and AT1 receptors (AT1R), induced by the $2 \mathrm{~K} 1 \mathrm{C}$ experimental model, is mediated through proinflammatory activation of the immune system (27). Moreover, inflammatory cell recruitment is associated with the development of left ventricular fibrosis and remodeling in the hypertensive heart (28), as demonstrated by the increase of connective tissue in the $2 \mathrm{~K} 1 \mathrm{C}$ animals of the present study. Similarly, increased renal inflammation is associated with 
greater tissue fibrosis and loss of renal function (29), which is in agreement with the histological findings of the present study.

It is known that in addition to vasoconstriction, angiotensin II can induce oxidative stress due to the stimulation of AT1R by activation of the NADH/NADPH oxidase enzyme in vascular cells, increasing intracellular synthesis of ROS (30). Thus, oxidative stress is associated with the activation of inflammatory processes (31), this is consistent with the increased production of cytokines or growth factors found in the hypertensive rats in the present study. The results obtained in the present study demonstrated that hypertension led to increased oxidative stress in the kidneys, as indicated by the increase of TBARS. However, the activity of superoxide dismutase was not examined and is a limitation of the present study. Previous studies involving animal models of hypertension have shown that an abundance of ROS, due either to their increased production or their decreased degradation, determines the extent of oxidative damage in tissues (32-34). However, in the present study, no differences were observed in the levels of lipid peroxidation between the sham and $2 \mathrm{~K} 1 \mathrm{C}$ groups in the liver and heart, although an increased level of TGF- $\beta 1$ was observed. Whereas elevated lipid peroxidation is associated with liver damage (35), the results obtained in the liver in the present study supported the fact that a precise balance between the levels of ROS and the corresponding antioxidants is important for maintaining proper cellular functions (36). In the heart, the levels of -SH groups were increased in an attempt to protect itself against oxidative damage. This is likely to be the reason that no alterations in the levels of TBARS were observed.

In addition to the inflammatory damage induced by hypertension, as shown by the increased levels of proinflammatory molecules, fibroblast markers and collagen deposition, it was also observed that epithelial and mesenchymal genes were differentially expressed in the kidneys, leading to the occurrence of EMT. This phenotype in the renal cells was observed as a reduction in the expression of E-cad and an increase of the mesenchymal/fibroblast markers such as N-cad, $\alpha-S M A$ and COL1A1. These changes were associated with the loss of tubular epithelial cells and increased amounts of connective tissue. Both increased proliferation of resident fibroblasts (and/or collagen) and epithelial cells undergoing EMT may be associated with the release of TGF- $\beta 1$ (37). Consistent with this hypothesis, the upregulated expression of $\mathrm{N}$-cad and COL1A1 in only the clipped kidney can be explained by the increase of TGF- $\beta 1$ and IL- 6 in this organ. Moreover, while an increased level of COL1A1 expression was observed, the level of COL3A1 was reduced. This is indicative of the synthesis of collagen type III gradually being replaced by collagen type I in the early stages of renal fibrosis (38). The transition of tubular epithelial cells into cells with mesenchymal features results in functional debility and an increased regenerative response, inducing an immunological reaction and recruitment of myofibroblasts (39). The increased gene expression of $\alpha$-SMA, as well as other data of the present study, supported these findings. Furthermore, there is evidence that oxidative stress is involved in the pathogenesis of TGF- $\beta 1$-induced EMT through the activation of mitogen-activated protein kinase and Smad pathways (40).
The HGF gene showed differential expression in the kidneys of the hypertensive animals. Therefore, increased mRNA expression of the HGF gene in the left kidney, together with its decreased expression in the contralateral kidney, was indicative of the stimulation of the transcriptional regulation of this gene in an attempt to counter the fibrotic action of TGF- $\beta 1$. One of the activities of TGF- $\beta 1$ is the negative regulation of the transcription of E-cad and other components of AJs, leading to the loss of epithelial intercellular adhesion, which is associated with cellular delamination from the epithelial layer (41). This phenomenon was observed in the present study, with the decreased expression of E-cad transcripts in the kidneys being explained by the increased expression of TGF- $\beta 1$. However, other factors may be involved in the negative regulation of E-cad expression, such as microRNA-214-3p, under hypoxic conditions (42), as well as the zinc finger protein SNAI1 family of transcription factors during embryo development and tumor progression (43). In another model of hypertension, the consumption of dietary salt induced renal fibrosis and tubular EMT, as identified by reduced E-cad expression and increased $\alpha$-SMA expression (44).

In the present study, the increased blood pressure led to an increase in the area occupied by collagen fibers in the cardiac tissue, which was associated with the increased expression of the COL1A1 gene, a marker of fibrosis. These findings were supported by the increased levels of the TGF- $\beta 1$ profibrotic cytokine in the hypertensive animals, as well as by the increased expression of the $\mathrm{N}$-cad and $\alpha$-SMA mesenchymal markers. The increased expression of $\mathrm{N}$-cadherin has been observed in animals with hypertrophic hearts (45). The transformation of cardiac fibroblasts into myofibroblasts is predominantly promoted by TGF- $\beta 1$ and other growth factors, resulting in the excessive production of extracellular matrix proteins (7). In the process of cardiac fibrosis, the level of $\alpha$-SMA increases during transdifferentiation of the fibroblasts into myofibroblasts (46). The expression of E-cad was positively regulated by hypertension, consequently, the transdifferentiation from endothelial to mesenchymal phenotype was not observed, despite the high levels of TGF- $\beta 1$ in the heart. Considering that the dynamic control of E-cad is fundamental in establishing and maintaining the junctions between epithelial cells (47), the increased gene expression observed was suggestive of an attempt to restore cardiac function. This hypothesis was supported by the increased gene expression of HGF, which negatively regulates the transformation of cardiac fibroblasts in response to TGF- $\beta 1(48,49)$. On the other hand, partial EndMT may also occur (39), in which cells exhibit both endothelial and mesenchymal markers and, therefore, have a hybrid phenotype $(50,51)$.

In the normal liver, the expression of TGF- $\beta 1$ is low; however, higher expression occurs in the case of liver damage (52). Despite the increased levels of the proinflammatory cytokines TGF- $\beta 1$ and TNF- $\alpha$ in the liver of the hypertensive animals, the epithelial E-cad and the mesenchymal N-cad, $\alpha$-SMA and COL1A1 gene transcripts were not modulated by hypertension. There were also no changes in the expression of the COL3A1 and HGF genes, or the cellular organization of the hepatic tissue. The data from the present study suggested that during the 28 day experimental period, renovascular hypertension did not cause damage to the liver tissue as there was no proliferation of hepatocytes or activation 
of hepatic stellate cells, which would lead to fibrosis (53). Therefore, it is hypothesized that these results indicate that the hepatic antioxidant capacity stimulated a protective mechanism for the tissue. Thus, the epithelial/endothelial and mesenchymal genes expressed in the liver, heart and kidneys are differentially regulated by renovascular hypertension. Collectively, the data indicated that renovascular hypertension caused renal damage that stimulated the transcription of EMT/EndMT genes in the kidneys and the heart. However, in the heart, these genes were differentially modulated, which may occur to maintain cardiac function.

\section{Acknowledgements}

The authors would like to thank Dr Cibele M. Prado (Department of Pathology, Ribeirão Preto Medical School, University of São Paulo, Brazil) for the surgical training provided.

\section{Funding}

The current study was supported by Fundação Hermínio Ometto/FHO (Araras, SP, Brazil; grant no. 2017/345).

\section{Availability of data and materials}

The datasets used and/or analyzed during the current study are available from the corresponding author on reasonable request.

\section{Authors' contributions}

CAO conceived and designed the experiments. LRF, BCM, GSRQ, RFF, MAME, MF and AAA performed the experiments. CAO and BFT analyzed the data. CAO wrote the manuscript. All authors read and approved the final manuscript.

\section{Ethics approval and consent to participate}

The experimental procedures in the present study were performed with the approval of the Ethics Committee on Animal Use of University Center of the Hermínio Ometto Foundation (Araras, Brazil).

\section{Patient consent for publication}

Not applicable.

\section{Competing interests}

The authors declare that they have no competing interests.

\section{References}

1. Levy D, Larson MG, Vasan RS, Kannel WB and Ho KK: The progression from hypertension to congestive heart failure. JAMA 275: 1557-1562, 1996.

2. Khangura KK, Eirin A, Kane GC, Misra S, Textor SC, Lerman A and Lerman LO: Cardiac function in renovascular hypertensive patients with and without renal dysfunction. Am J Hypertens 27 $445-453,2014$.
3. Chade AR, Rodriguez-Porcel M, Grande JP, Krier JD, Lerman A, Romero JC, Napoli C and Lerman LO: Distinct renal injury in early atherosclerosis and renovascular disease. Circulation 106: 1165-1171, 2002.

4. Crowley SD: The cooperative roles of inflammation and oxidative stress in the pathogenesis of hypertension. Antioxid Redox Signal 20: 102-120, 2014

5. Oliveira-Sales EB, Dugaich AP, Carillo BA, Abreu NP, Boim MA Martins PJ, D'Almeida V, Dolnikoff MS, Bergamaschi CT and Campos RR: Oxidative stress contributes to renovascular hypertension. Am J Hypertens 21: 98-104, 2008.

6. Lim YS, Lee HC and Lee HS: Switch of cadherin expression from E- to N-type during the activation of rat hepatic stellate cells. Histochem Cell Biol 127: 149-160, 2007.

7. Wu M, Peng Z, Zu C, Ma J, Lu S, Zhong J and Zhang S: Losartan attenuates myocardial endothelial-to-mesenchymal transition in spontaneous hypertensive rats via inhibiting TGF- $\beta / \mathrm{Smad}$ signaling. PLoS One 11: e0155730, 2016.

8. Chade AR, Zhu XY, Grande JP, Krier JD, Lerman A and Lerman LO: Simvastatin abates development of renal fibrosis in experimental renovascular disease. J Hypertens 26: 1651-1660, 2008.

9. Fragiadaki M and Mason RM: Epithelial-mesenchymal transition in renal fibrosis-evidence for and against. Int J Exp Pathol 92: 143-150, 2011.

10. Niessen CM, Leckband D and Yap AS: Tissue organization by cadherin adhesion molecules: Dynamic molecular and cellular mechanisms of morphogenetic regulation. Physiol Rev 91: 691-731, 2011.

11. Katsamba P, Carroll K, Ahlsen G, Bahna F, Vendome J, Posy S, Rajebhosale M, Price S, Jessell TM, Ben-Shaul A, et al: Linking molecular affinity and cellular specificity in cadherin-mediated adhesion. Proc Natl Acad Sci USA 106: 11594-11599, 2009.

12. Gumbiner BM: Cell adhesion: The molecular basis of tissue architecture and morphogenesis. Cell 84: 345-357, 1996.

13. Murphy F, Waung J, Collins J, Arthur MJ, Nagase H, Mann D, Benyon RC and Iredale JP: N-Cadherin cleavage during activated hepatic stellate cell apoptosis is inhibited by tissue inhibitor of metalloproteinase-1. Comp Hepatol 3 (Suppl 1): S8, 2004.

14. Guarino M, Tosoni A and Nebuloni M: Direct contribution of epithelium to organ fibrosis: Epithelial-mesenchymal transition. Hum Pathol 40: 1365-1376, 2009.

15. Voutsadakis IA: HER2 in stemness and epithelial-mesenchymal plasticity of breast cancer. Clin Transl Oncol 21: 539-555, 2019.

16. Wang $\mathrm{H}$ and Unternaehrer JJ: Epithelial-mesenchymal transition and cancer stem cells: At the crossroads of differentiation and dedifferentiation. Dev Dyn 248: 10-20, 2019.

17. Yu K, Li Q, Shi G and Li N: Involvement of epithelial-mesenchymal transition in liver fibrosis. Saudi J Gastroenterol 24: 5-11, 2018.

18. Chen DQ, Feng YL, Cao G and Zhao YY: Natural products as a source for antifibrosis therapy. Trends Pharmacol Sci 39: 937-952, 2018.

19. Goldblatt H, Lynch J, Hanzal RF and Summerville WW: Studies on experimental hypertension: I. The production of persistent elevation of systolic blood pressure by means of renal ischemia. J Exp Med 59: 347-379, 1934.

20. Esterbauer $\mathrm{H}$ and Cheeseman KH: Determination of aldehydic lipid peroxidation products: Malonaldehyde and 4-hydroxynonenal. Methods Enzymol 186: 407-421, 1990.

21. Faure P and Lafond JL: Measurement of plasma sulfhydryl and carbonyl groups as a possible indicator of protein oxidation. In: Analysis of Free Radicals in Biological Systems. Favier AE, Cadet J, Kalyanaraman B, Fontecave M and Pierre JL (eds). Birkhäuser, Basel, pp237-248, 1995.

22. Hiyoshi H, Yayama K, Takano M and Okamoto H: Angiotensin type 2 receptor-mediated phosphorylation of eNOS in the aortas of mice with 2-kidney, 1-clip hypertension. Hypertension 45: 967-973, 2005.

23. Mehta PK and Griendling KK: Angiotensin II cell signaling: Physiological and pathological effects in the cardiovascular system. Am J Physiol Cell Physiol 292: C82-C97, 2007.

24. Janicki JS, Brower GL, Gardner JD, Chancey AL and Stewart JA Jr: The dynamic interaction between matrix metalloproteinase activity and adverse myocardial remodeling. Heart Fail Rev 9: 33-42, 2004.

25. Peotta VA, Gava AL, Vasquez EC and Meyrelles SS: Evaluation of baroreflex control of heart rate in renovascular hypertensive mice. Can J Physiol Pharmacol 85: 761-766, 2007.

26. Ding $\mathrm{Y}$ and Choi ME: Regulation of autophagy by TGF- $\beta$ : Emerging role in kidney fibrosis. Semin Nephrol 34: 62-71, 2014. 
27. Singh MV, Chapleau MW, Harwani SC and Abboud FM: The immune system and hypertension. Immunol Res 59: 243-253, 2014.

28. Levick SP, McLarty JL, Murray DB, Freeman RM, Carver WE and Brower GL: Cardiac mast cells mediate left ventricular fibrosis in the hypertensive rat heart. Hypertension 53: 10411047,2009

29. Matavelli LC, Huang J and Siragy HM: Angiotensin $\mathrm{AT}_{2}$ receptor stimulation inhibits early renal inflammation in renovascular hypertension. Hypertension 57: 308-313, 2011.

30. Endtmann C, Ebrahimian T, Czech T, Arfa O, Laufs U, Fritz M Wassmann K, Werner N, Petoumenos V, Nickenig G and Wassmann S: Angiotensin II impairs endothelial progenitor cell number and function in vitro and in vivo: Implications for vascular regeneration. Hypertension 58: 394-403, 2011.

31. Skultetyova D, Filipova S, Riecansky I and Skultety J: The role of angiotensin type 1 receptor in inflammation and endothelial dysfunction. Recent Pat Cardiovasc Drug Discov 2: 23-27, 2007.

32. Polizio AH and Peña C: Effects of angiotensin II type 1 receptor blockade on the oxidative stress in spontaneously hypertensive rat tissues. Regul Pept 128: 1-5, 2005.

33. Dornas WC, Silva M, Tavares R, de Lima WG, dos Santos RC, Pedrosa ML and Silva ME: Efficacy of the superoxide dismutase mimetic tempol in animal hypertension models: A meta-analysis. J Hypertens 33: 14-23, 2015.

34. Rizzi E, Ceron CS, Guimaraes DA, Prado CM, Rossi MA, Gerlach RF and Tanus-Santos JE: Temporal changes in cardiac matrix metalloproteinase activity, oxidative stress, and TGF- $\beta$ in renovascular hypertension-induced cardiac hypertrophy. Exp Mol Pathol 94: 1-9,2013.

35. Seif HSA: Physiological changes due to hepatotoxicity and the protective role of some medicinal plants. Beni-Suef Univ J Basic Appl Sci 5: 134-146, 2016.

36. Valko M, Leibfritz D, Moncol J, Cronin MT, Mazur M and Telser J: Free radicals and antioxidants in normal physiological functions and human disease. Int J Biochem Cell Biol 39: 44-84, 2007.

37. Correa-Costa M, Semedo P, Monteiro AP, Silva RC, Pereira RL, Gonçalves GM, Marques GD, Cenedeze MA, Faleiros AC, Keller AC, et al: Induction of heme oxygenase-1 can halt and even reverse renal tubule-interstitial fibrosis. PLoS One 5: e14298, 2010

38. Genovese F, Manresa AA, Leeming DJ, Karsdal MA and Boor P: The extracellular matrix in the kidney: A source of novel noninvasive biomarkers of kidney fibrosis? Fibrogenesis Tissue Repair 7: 4, 2014.

39. Lovisa S, LeBleu VS, Tampe B, Sugimoto H, Vadnagara K, Carstens JL, Wu CC, Hagos Y, Burckhardt BC, PentchevaHoang T, et al: Epithelial-to-mesenchymal transition induces cell cycle arrest and parenchymal damage in renal fibrosis. Nat Med 21: 998-1009, 2015.

40. Wang Y, Pang L, Zhang Y, Lin J and Zhou H: Fenofibrate improved interstitial fibrosis of renal allograft through inhibited epithelial-mesenchymal transition induced by oxidative stress. Oxid Med Cell Longev 2019: 8936856, 2019.

41. Chen Y, Luo Q, Xiong Z, Liang W, Chen L and Xiong Z: Telmisartan counteracts TGF- $\beta 1$ induced epithelial-tomesenchymal transition via PPAR- $\gamma$ in human proximal tubule epithelial cells. Int J Clin Exp Pathol 5: 522-529, 2012.
42. Liu M, Liu L, Bai M, Zhang L, Ma F, Yang X and Sun S: Hypoxia-induced activation of Twist/miR-214/E-cadherin axis promotes renal tubular epithelial cell mesenchymal transition and renal fibrosis. Biochem Biophys Res Commun 495: 2324 2330, 2018

43. Nieto MA and Cano A: The epithelial-mesenchymal transition under control: Global programs to regulate epithelial plasticity. Semin Cancer Biol 22: 361-368, 2012.

44. Wang Y, Mu JJ, Liu FQ, Ren KY, Xiao HY, Yang Z and Yuan ZY: Salt-induced epithelial-to-mesenchymal transition in Dahl saltsensitive rats is dependent on elevated blood pressure. Braz J Med Biol Res 47: 223-230, 2014

45. dos Santos DO, Blefari V, Prado FP, Silva CA, Fazan R Jr, Salgado HC, Ramos SG and Prado CM: Reduced expression of adherens and gap junction proteins can have a fundamental role in the development of heart failure following cardiac hypertrophy in rats. Exp Mol Pathol 100: 167-176, 2016.

46. Liu G, Liang B, Song X, Bai R, Qin W, Sun X, Lu Y, Bian Y and Xiao C: P-selectin increases angiotensin II-induced cardiac inflammation and fibrosis via platelet activation. Mol Med Rep 13: 5021-5028, 2016.

47. Canel M, Serrels A, Anderson KI, Frame MC and Brunton VG: Use of photoactivation and photobleaching to monitor the dynamic regulation of E-cadherin at the plasma membrane. Cell Adh Migr 4: 491-501, 2010.

48. Okayama K, Azuma J, Dosaka N, Iekushi K, Sanada F, Kusunoki H, Iwabayashi M, Rakugi H, Taniyama $\mathrm{Y}$ and Morishita R: Hepatocyte growth factor reduces cardiac fibrosis by inhibiting endothelial-mesenchymal transition. Hypertension 59: 958-965, 2012

49. Yi X, Li X, Zhou Y, Ren S, Wan W, Feng G and Jiang X: Hepatocyte growth factor regulates the TGF- $\beta 1$-induced proliferation, differentiation and secretory function of cardiac fibroblasts. Int J Mol Med 34: 381-390, 2014.

50. Nieto MA, Huang RY, Jackson RA and Thiery JP: Emt: 2016. Cell 166: 21-45, 2016.

51. Jolly MK, Ward C, Eapen MS, Myers S, Hallgren O, Levine H and Sohal SS: Epithelial-mesenchymal transition, a spectrum of states: Role in lung development, homeostasis, and disease. Dev Dyn 247: 346-358, 2018

52. Jones CN, Tuleuova N, Lee JY, Ramanculov E, Reddi AH, Zern MA and Revzin A: Cultivating hepatocytes on printed arrays of HGF and BMP7 to characterize protective effects of these growth factors during in vitro alcohol injury. Biomaterials 31: 5936-5944, 2010

53. Xie G and Diehl AM: Evidence for and against epithelial-tomesenchymal transition in the liver. Am J Physiol Gastrointest Liver Physiol 305: G881-G890, 2013.

This work is licensed under a Creative Commons Attribution-NonCommercial-NoDerivatives 4.0 International (CC BY-NC-ND 4.0) License. 